\title{
On the Possibility of a Phenomenology of Light
}

\author{
Nolen Gertz
}

Husserl, Heidegger, and Levinas have in common a peculiar preoccupation with light. This is not to suggest that light itself was the theme of their study, but rather that in the course of their work, for one reason or another, light became a peculiar object of concern. Hence what will be attempted here is an effort to pull out a thread - a thread we shall have to tie to Plato - to see if something like a phenomenology of light can be sewn together from it.

Each account of light will be presented, from Husserl to Levinas, but in each case we shall be forced to follow the account beyond its origin, and in the end I shall argue that a difficult return to light is necessary.

\section{Husserl: Light as "Circumstance" of "Apperception"}

To best understand how and why light is meaningful for Husserl, we need simply look to the transition he makes between the first volume of his Ideas ("General Introduction to Pure Phenomenology") and the second ("Studies in the Phenomenology of Constitution"). In Ideas I we find Husserl attempting to explain and justify his new eidetic science, phenomenology. Phenomenology intends to investigate normal, everyday lived experience, what he termed the "natural attitude" (51), through the radical methodological tool of the epoché, the "parenthesizing" or "excluding" (59) of all contingent and theoretical aspects of experience so as to arrive at the "phenomenological attitude" (66). It is through such an attitude that we can most 
accurately describe what actually makes up lived experience, that is, its essential character of being composed of a series of conscious acts. We find then that conscious acts are always of the form "consciousness of" something, wherein the acts and their objects are related in a determinate way. To summarize, phenomenology brings about the "reduction" of lived experience so as to investigate what is left over, its "residuum" (65), which is the wholly new, and up until now, uninvestigated "field of absolute consciousness" (113). ${ }^{1}$

What we find within this field is a Pure Ego, otherwise referred to as the Cogito, which is the subject of the acts of consciousness or cogitationes, and the content of the acts, the cogitatum. The relationship between the three constituents of consciousness is contained in the concept of intentionality. Thus in perceiving an object, I "seize upon" (69) that object through the intentional act. There are other objects that surround the object of my perception, but until I turn my regard to them, they remain "background-intuitions" of my perception (70). In the "free turning" of my regard, I turn objects that are potentially perceivable into objects of which I am "explicitly" conscious (71). What is of importance to Husserl in these meditations is the "essence" of the acts, that is, what distinguishes acts of consciousness such as "seeing" from other acts such as "judging," and what separates the perception of "things" from the perception of "feelings," "memories," "wishes," etc. (75-78). Husserl's concern therefore is to clarify what takes place in the "unity of the stream of mental processes" (80) that characterizes our mundane lived experience. In this way we are able to describe how the natural attitude obscures our awareness of the "truth" of our experience, such that we are necessarily led to make "errors" when we try to explain perception and thus find ourselves, for example, making distinctions between things as they appear to us and "things-in-themselves" (92-104). 
It is not difficult to see therefore why the Husserl of Ideas I would be interested in light only insofar as it exists as a potential cogitatum. But for the Husserl of Ideas II, light became something far more important. For it is in this work, where we find Husserl changing his focus from the realm of conscious acts to the world of things that "motivate" (21) these acts, that light's involvement in perception can be given its proper consideration. This is due to his realization that we must "repair a deficiency" of considering "things in isolation," and instead admit that "it is in relation to 'circumstances' that the thing is what it is" (44). Thus we must not limit an investigation into "thing-consciousness" to its bare essential components of "thing" and "consciousness-of things," for in so doing we lose sight of the fact that we come across things in a determinate way, a way that is determined not solely by our consciousness but also by the "circumstances" in which we originally find things.

The circumstances surrounding our perception of a thing condition the perception, and do so in a "causal" (48) way. There are many factors that contribute to how we see something, but what is of importance is that these factors contribute to perception in a strict, regulated fashion. In certain circumstances we see certain things in a certain way. This can be more rigorously defined by approaching the situation as one that allows for perception to move within levels of “indeterminacy" (38). There are then circumstances which provide for "optimum" conditions of perception, what we otherwise refer to as the "normal" conditions for perceiving a thing. Light of course functions as such a circumstance, where the absence of light, that is, darkness, and "clear daylight," operate as the "limit-conditions" of the possible determinacy of an object (64-65).

As is the case with anything that follows particular causal rules, over time we acquire an "experiential knowledge" (66) of the rules and how they operate. It is owing to the accumulation of knowledge that I do not perceive things simply, as though in each case I see something as 
though I see it "for the first time," but rather that I come to "apperceive" things (66). Thus I come to form expectations of how things "should" look, and can distinguish between things given "properly" and things "seemingly given" (67). "This belongs to the general question of the constitution of a thingly unity as an apperceptive unity of a manifold of different levels which themselves are already apperceived as unities of multiplicities" (66). It is because of this "apperceptive unity" that I can explain how the appearance of a thing can change under different circumstances, even if the circumstances are not themselves immediately apparent. It is because of this that when there is a "change in relation to causal circumstances, as, for example, each advent of an illuminating body... I can apprehend the change without seeing such an illuminating body, but in that case the causal circumstance is, in an indeterminate way, co-apperceived" (67).

And yet, though this applies to all circumstances, it does not apply to all circumstances equally. Even though light is a circumstance, it is not, as Husserl points out, a circumstance like any other. This comes out while Husserl is describing the role of the lived-body in perceptual experience, and how the body itself can be perceived as a "material thing" because of the role it plays in the "causal nexus of material nature" (167). Yet the body's role is slightly different from other material things insofar as when the circumstances of my perception of it change, the change is not simply physical, but "psychophysical" (69), since we can experience the changes as they occur. But there is a distinction to be made here when the change is of the lighting conditions surrounding my body, as for example when there is a "red illumination of my hand" (168). Husserl argues that this case is different since it cannot be "split apart abstractively into a physical process and its 'psychical' consequence (or vice versa)," because "the physical process to which the sensation of the color is linked - red light rays striking my eyes - is not given to me 
at all. The 'turning point,' which lies in the Body, the point of the transformation from causal to conditional process, is hidden from me" (168).

But how then do I know my hand is under illumination and not simply turning red? I know, not because I "perceive" the illumination, but rather because I "apperceive" it. It is from combining the seeing of the consequences of a particular lighting condition with my experiential knowledge of light as a condition that I am able to determine what is actually taking place. What we can take from all this is that light is a circumstance, but a circumstance that cannot be understood immediately (as others can), insofar as it requires a certain level of understanding to "see" it properly. Light has gone from a possible object of intentional acts of perception to a significantly unperceived effect on such acts.

Although Husserl sees light as serving a specifically unique role-in his discussion of "optimum" circumstances for seeing an object he notes that "a privilege attaches to clear daylight" (65) - the primary questions of what it means to see light, and how to describe what light is and does, are raised only to the extent that they illuminate features of lived experience, and are left largely unanswered, a peculiar result for a descriptive analysis of the things themselves.

The thread is picked up by Heidegger who, referring back to Plato, develops an account of the importance and uniqueness of light, but as we shall see Heidegger is even more guilty of leaving the primary questions unanswered.

\section{Heidegger: Light as "Stand In" for the "Unsayable"}

Husserl was led to knowledge of light as a circumstance of perception. The relationship between light and knowledge is central to Heidegger in his investigation of Plato's "Allegory of 
the Cave" in his work, The Essence of Truth. Heidegger radically widens the realm of "experiential knowledge" to not be simply considered "genetically," as Husserl put it, and thus from the perspective of knowledge gained over time, but rather as also containing something we might refer to as a "mythico-historical" dimension. The new dimension arises out of Heidegger's project to use phenomenology not for the investigation of consciousness and intentionality, but rather for the investigation of the Being of beings. The history of philosophy is the history of the questioning of Being, a questioning that has become lost and confused over time, and is thus in need of an awakening.

As the title of the work indicates, Heidegger's aim here is to determine how the "essence" of "truth" evolved from its primordial relationship with "unhiddenness," as disclosed in the Greek term aletheia, to the more modern conception of truth as "correspondence" (6-7). This is not to say however that Heidegger is suggesting that the evolution can simply be charted historically, as though the Ancient Greek aletheia was simply eclipsed by the Latin adequatio and developed in this way into the propositional logic we have today. Both versions of truth already existed in Greece: the Ancient world already contained within itself simultaneously the primordial and the modern. It is for this reason that we find Heidegger wrestling with Plato's allegory, for he believes that it is there that we can discover "how already in the classical time of ancient philosophy the double-meaning of the concept of truth is formed, but without the intertwinings and inner connections being seen" (12).

The allegory in question is found in Book VII of Plato's Republic and, according to Plato, is meant to describe the effects of education on the soul. Of course such an explanation does not satisfy Heidegger, and thus he tries to uncover what is really going on in the allegory through a closer reading of the Greek text. But why is the ancient allegory of such importance for 
Heidegger, or for us? Because after Plato's brief explanation of the meaning of the allegory he goes on to tell us that the situation of the prisoners is our situation, the situation of all of humanity. The shadows the prisoners see on the walls, which are all they have ever experienced, are meant to represent what we see of the world around us, which is all we have ever experienced. But of course the prisoners are incapable of realizing that what they see are merely shadows, just as we are incapable of seeing that there is more to experience than that which is immediately given to us. They, like us, think that what they see is "real" because their actual situation is "hidden" from them. To be freed from this bondage, to be liberated, is thus to be brought into the light, for it is through light, sunlight, that the world, and our situation in it, becomes "unhidden" (29).

The question becomes: if the prisoners represent humanity and the cave represents the world, then what does the light represent? As Heidegger points out, there is both the light of the fire in the cave and the light of the Sun above. Thus the two sources of illumination must have two different meanings attached to them. Consequently, though what emanates from the two sources is referred to as "light" in both cases, "light" must itself be capable of having two different meanings. Hence just as "truth" can be understood as either adequatio and correspondence or as aletheia and unhiddenness, so too can "light" bear within itself a conceptual distinction.

Heidegger sees in this possible distinction the clue to properly interpreting Plato's allegory.

There is indeed brightness, 'light', inside the cave, but from behind. The prisoners have no relationship to light as light, for neither do they see the fire that casts the light. [...] All this, things that cast shadows, fire that makes shadows possible, is opisthen, behind their backs, as distinct from ta prosthen, what they see before 
them. Only the latter is unhidden; the former remains hidden. Here, therefore, being human also means, among other things: to stand within the hidden, to be surrounded by the hidden... (20-21)

According to Heidegger, light can therefore be seen as illumination, as "brightness," but it can also be understood with regard to its relationship to truth, to unhiddenness, to liberation, and to freedom. Light is more than just brightness, than illumination; it is what (if we may be allowed to create our own Heideggerian turn of phrase) "lets-things-be-seen-in-theirunhiddenness." Not unlike for Husserl, light is something of a familiar but elusive condition of seeing what is lit up.

What we find is that, like "truth," our understanding of "light" has evolved from a primordial to a more modern conception. However, with regard to light, Heidegger prefers to contrast the primordial with the "artificial." According to Heidegger, "looking into the light, when it is only a light, does not suffice: light and light is not the same. Therefore our heading: the genuine liberation of man to the primordial light" (31). How can light be different from light? When light from a fire is taken to be artificial as opposed to light from the Sun. But to understand this properly we must remember that in the allegory fire is not fire and the Sun is not the Sun, for both are meant to represent something else. In fact, if we also remember that the prisoners in the cave stand for our situation in the world, then we can see that the fire represents the Sun, which is confirmed by Plato himself towards the end of the allegory. Thus, contrary to what we might have expected, it is the light of the Sun that is taken to be "artificial." But what then is the "primordial" light, and what does the Sun represent?

To properly answer this question we must first clarify the relationship between light and sight. Heidegger points out that when we see, the fact that "we would never see anything like a 
book were we not able to see in another more primordial sense" (37), has become lost to us. It is this "more primordial" sense of sight that for Heidegger allows us to see things in their "whatbeing," or, as Plato famously put it, is the seeing of "Ideas." To be able to see something as something, not as a mere bundle of sensations, requires a certain "comportment" towards things. Thus to be able to see things as they are requires that we must already in some sense "know" what we are looking at. In our original situation in the cave all we see is shadows, but that they are shadows is "hidden" from us, for we do not see what they really are. It is not until we become aware of this distinction between seeing as seeing and seeing as knowing that we can see things properly. To put it another way, we can say it is the seeing of Ideas that "lets-things-be-seen-intheir-unhiddenness."

With this formulation, a formulation we have already come across, we can finally answer the question of what the Sun and sunlight "stand for" in this allegory. If the fire in the cave represents the actual Sun and its light represents the mundane way of seeing things, then the seeing of Ideas is represented by the light outside the cave, and that highest of Ideas for Plato, the Idea of the Good, is what is represented by the Sun. But what is more important for us here, as Heidegger indicates, is that this imagery, this symbolism, was not simply born out of Plato's poetic spirit, but was rather required by the object of the investigation itself. If in our "natural" comportment towards things what they are is "hidden" from us, and if we must become "free" so as to see the world in its "truth," then what allows for this liberation, the Ideas, must necessarily be even more "hidden." Thus what gives rise to the Ideas themselves, the Idea of the Good, is what is most hidden: it is the "unsayable" (71).

The only way to "say" anything about the "unsayable" is to use an indirect means of communication, to use something of which we can speak, something that can "stand in" for the 
"unsayable" and be a "symbol" for it (72). Indeed Plato says more about the symbolic unsayable: not only does the Sun fill the world with light, but it is also the source of life, what must already exist for there to be any life in the world. "The overall correspondence of the symbolism is that, just as light requires another source, so do the ideas themselves presuppose another idea standing over them, the good" (77). Light is not merely what lets things be seen, it is also what allows us to speak of and philosophize about our very capacity to know things, to have knowledge. As Heidegger argues, and in anticipation of what we will see with Levinas, Plato's goal was to teach us that "only when this whole path of liberation has been traversed in all its stages, with full commitment to inquiry and investigation, does there occur the flash and illumination of understanding" (81, emphasis added). It is only because of light's ability to "double" as a "symbol for the unsayable" that we can have anything like philosophy in the first place, for what is philosophy if not the attempt to articulate that which is either believed to be unspeakable (e.g. the questions of metaphysics) or thought to be not worth speaking about (e.g. to question the everyday)? Following Plato, Heidegger has gone beyond Husserl's recognition that light's role in our perception cannot be described like any other circumstance, and pointed to light's extraperceptual role, how it carries with it a meaning and significance that lends itself to being not just looked at, but worshipped. Levinas will pick up this thread and take over the seeming impossibility of describing the indescribable characteristics of light, struggling to see not just light's relationship to truth, but to our very existence.

\section{Levinas: Light as "Rival" to the "There is"}

For Levinas, Existence is not simply the totality of existents, but what we find in the impenetrability of the night, in the "fact that there is" (8). In the darkness of the night there are 
no longer people or places, objects or forms, but only the feeling of a nowhere that exists everywhere. But this nowhere that is devoid of things is not nothing, for it is rather the constant experience of something, a something that cannot be broken down into some things. It is in such an experience, when we lose sight of existents, that we are faced with Existence, with the there is... The ellipsis that tails this thought but does not close it, that keeps it interminably open, is the expression of what Levinas sees as the "pain" of this experience, of the "burden" that "wearies" us in the face of the void that is not empty, but instead "suffocates" us in its "fullness" (9-17). This is why the horror of death pales in comparison to the horror of Existence, for the horror of death is the fear that in death we will not escape from the night but be eternally consumed by it.

Fortunately for us the night is not everlasting, as every morning its borders are once again thrust back by the return of the Sun, and with it, the return of the world. And yet the onset of the light of day is not merely the revival of visibility and particularity. For Levinas, it is not simply the case that upon sunrise we wake up to the world once again so that we can go about our business. Rather, it is through light that we become who we are. Harkening back to Plato, Levinas tells us that light is the "condition for all beings," "whether it emanates from the sensible or from the intelligible sun" (40). We do not merely see things through light, but "light makes objects into a world, that is, makes them belong to us." Accordingly, "light makes possible, then, this enveloping of the exterior by the inward, which is the very structure of the cogito and of sense" (41). The inwardness that marks our subjectivity is opened up to the world through the light, through its ability to give us the world. Therefore, for Levinas, "the miracle of light is the essence of thought: due to the light an object, while coming from without, is already ours in the horizon which precedes it; it comes from an exterior already apprehended and comes into being as though it came from us, as though commanded by our freedom" (41). 
What should be beginning to be clear is that, if for Levinas it is in the night that we are lost, then it is in the light that we are found. Light does not just remove the ellipsis from the there is, it removes the there is itself. Light "illuminates and is naturally understood; it is comprehension itself" (9). This becomes the central concept for Levinas, insofar as his project to reclaim the "substantivity" of the subject revolves around the attempt to show that life is characterized by desire, a desire that our "existence in the world qua light" makes possible (43). When our inwardness is provoked by the exterior world there is far more taking place than an intentional act of consciousness. Our desires - to eat, to sleep, to live - allow us to escape from the "anonymity" of Being and to enter into relationships with things and with other people. These relationships, however, are not to be taken as the use of tools, or as part of our destiny, but as our genuine involvement with things and people as who and what they are, "in this world of light, where all is given" (85).

It is at this point that we might begin to wonder what exactly Levinas means by "light." The extraordinary widening of the function of "light" comes out most clearly when we see how easily Levinas moves from the reference to the "physico-mathematical explanation of the light which fills our universe" (40) to the idea that "the miracle of light is the essence of thought" (41). What Levinas is pointing to is his description of consciousness, of subjectivity, as "luminousness." The reason for this characterization is the parallel Levinas finds between "the way light is produced, as scintillation" (65), and "the scintillation of consciousness" (66), which later becomes the "scintillation of subjectivity" (90). This formulation is what allows him, as we have already seen, to talk of how light is what makes the world seem like it comes from us and to talk of the "solitude of light," that is, our solitude (86).

In order to try to better understand the movement of Levinas's approach to light we 
should look to his remarks on the two "senses" of light in Totality and Infinity. While trying to "distinguish look and language" (189) in the section entitled "Sensibility and the Face," Levinas returns to his analyses from Existence and Existents to once again discuss the role that light plays in "driving out darkness" and how "light conditions the relations between data," which "makes possible the signification of objects that border one another" (190-1). This presentation, which has so far maintained the thread of his previous considerations on light, is followed by a slight deviation in the form of a question and answer, and it is this discussion that shows that Levinas is perhaps not so far from the tradition that we have been tracing:

But is not light in another sense origin of itself - as the source of light, in which its being and its appearing coincide, as fire and as sun? Here, to be sure, is the figure of every relation with the absolute. But it is only a figure. The light as sun is an object. If in the diurnal vision light makes seen and is not seen, the nocturnal light is seen as source of light. In the vision of brilliancy, the juncture of light with object takes place. The sensible light qua visual datum does not differ from other data, and itself remains relative to an elemental and obscure ground. A relation with what in another sense comes absolutely from itself is needed to make possible the consciousness of radical exteriority. A light is needed to see the light. (191-2, emphasis added)

We have here returned once again to the bipolar treatment of light by phenomenology. And we can see further that it is a treatment that still views light as Plato did, as having the "being" of fire while "appearing" as the sun. This continuity of the tradition can also be found in the traces of Husserl ("light qua visual datum") and Heidegger (light qua "brilliancy") that can be seen in the description. Yet, the peculiarity of the Levinasian position that I have attempted to bring out would appear to be the distinction between "a light" and "the light" in the final sentence. But does this "another sense" - this duality that seemingly allows Levinas to posit light as both consciousness and the object of consciousness-properly belong to light qua light? In the movement from recognizing that light's uniqueness requires close study (Husserl), to opening up 
the analysis of light from what makes meaningful perception possible to what makes meaning itself possible (Heidegger), and finally to trying to see what it is about us that both makes us need light and connects us to it (Levinas), has phenomenology succeeded in describing light? Or, as Levinas perhaps makes clear, has it instead lost sight of what it is in experience that draws us to light in the first place and instead revealed something else entirely?

\section{Conclusion: "Light" versus "Lighting"}

We have now reached the point in our survey where we can ask if from out of it something like a phenomenology of light is possible. In order to try to answer this question we must first take a more critical stance and ask the more immediate question of what exactly Husserl, Heidegger, and Levinas mean by "light." For Husserl, light went from being understood as a possible object of intentional acts to something that has an effect on such acts, insofar as it causally determines how we see things. For Heidegger, light went from what is produced by means of a fire or the Sun to what allows us, through its symbolic possibilities, to say what would otherwise be unsayable (regarding the ground of truth). For Levinas, light went from something that physics or mathematics can describe to being the very substance of who we are.

In each of these thinkers we find a similar shift in focus in how they understand and make use of "light." Each began with a fairly simple description of our experience of light and slowly developed it into something else. Whether "light" became "illumination," "brightness," or "scintillation," for each the investigation moved further and further away from any possible discussion of light itself. In other words, since for each light was always a means rather than an end, light turned into a crucial concept, a deep symbol, or a fundamental theme, but never a phenomenon in phenomenology. This would seem to stem primarily from the fact that what in 
each case begins as an interest in the natural qualities of light is immediately passed over, since the interest is not in what light is or does but only in what light can become. ${ }^{2}$ To avoid these shifts, to bring the interest back to light itself, we must then focus our attention once again on whatever it is that originally draws our attention to light and linger there; otherwise we will be continually making the mistake of turning light into a tool for comprehension rather than into the end of contemplation that it deserves to reclaim.

So what might an endeavor to resolve this problem-this seemingly unavoidable obfuscation of light-look like? Since his analysis of the perceptual qualities of light was as close to a discussion of light for the sake of light that we came across, perhaps we should take Husserl as our guide_- but not the Husserl of the Ideas. Instead, if we move to the later Husserl, we can find in his essay "The Origin of Geometry" both an awareness of the danger that we have run into in each attempt to talk about light and a possible new approach to take. ${ }^{3}$ Though in this essay Husserl is calling our attention to how the practice of geometry has gone from something that was once taken up as meaningful, as something that we used and understood, to something that is now empty and that we learn only in the sense of memorizing the bare essentials from textbooks, still the idea of how this loss of meaning happens through the "seduction of language" (362) can be applied to the situation we have seen with light.

For what is our relationship to light if not what Husserl describes, that "greater and greater segments of this life lapse into a kind of talking and reading that is dominated purely by association; and often enough, in respect to the validities arrived at in this way, it is disappointed by subsequent experience" (362)? Hence just as Husserl saw the need to "reawaken" (359) our primordial relationship to geometry, to discover in what had become "sedimented" (361) a chain of discoveries and layers of experiences that could be followed back to the beginning, to the pre- 
scientific insights and self-evident realizations that gave birth to a scientific tradition, to allow what first gave life to the tradition to be taken up in the present to breathe new life into it, so too can we see such a need and such a possibility with light. In the same way that Husserl was able to search after the "first geometers" (354), or what has been referred to as the "proto-geometer," we too must use such methods to try to locate the "proto-architect," the theoretically necessary pre-historic person who originally discovered the relationships between light and space that existed before they got lost in our later discovery of "light" and "space." Therefore what we have found here, and would continue to uncover in such pursuits, is that to have something like a phenomenology of light we must first, as Husserl would put it, seek after the "origin of light," so as to finally determine in the phenomenological attitude in what way "illumination," "brightness," and "scintillation" can help us to better see light and in what way they might actually help obscure it. Yet even though this leaves us with loose ends instead of something knitted together into the sort of investigation that was hoped for at the outset, it has at least provided us with a guide toward such an end, which is, considering the ever-receding tendency of phenomenology, perhaps the best we could hope for.

\section{Notes}

${ }^{1}$ This explains Husserl's comparison of his project to Descartes'. For just as Descartes sought to call attention to the implicit dangers of our natural habit of taking the world for granted, by radically doubting everything until something certain was left over, so Husserl seeks to call attention to the naïveté of our everyday relation to the world-and in particular how that relationship reinforces the naïveté by blinding us to its existence - by radically changing our attitude to the world through making that very attitude itself the theme of his investigations to reveal the hidden primordial relationship between consciousness and the world. However, whereas for Descartes to understand the world we had to first understand our clear and distinct ideas of it, for Husserl to understand the world we must first understand how it is that we have 
consciousness of the world, how the world is "given" (5) to us, and how, in turn, we give ourselves the world.

2 This is perhaps most explicitly expressed by Levinas when he writes: "Whatever may be the physico-mathematical explanation of the light which fills our universe, phenomenologically it is a condition for phenomena, that is, for meaning" (40). Before we can make such a move must we not first explore the connection between the "physico-mathematical explanation" of light and the way that that very same phenomena can yet be a "condition" for "meaning"? Otherwise we seem to run the risk of constantly making statements about light such as Levinas' aforementioned claim that "light is produced, as scintillation" and can thus be compared to the "scintillation of consciousness," without having a firm grasp on what is meant here by "scintillation." Consequently, this parallel does not allow us to better understand consciousness through our understanding of light, as would appear to be the case, since instead we must try to use Levinas' subsequent discussion of consciousness to piece together some sense of what he means by light.

${ }^{3}$ Though it may be argued that there are better resources than Husserl for what I am attempting here in turning to his "Origin of Geometry" for an idea of how to proceed in this investigation, I would contend that Husserl provides us with a more useful approach to understanding an object under study than, say, we can find in Heidegger's "Origin of the Work of Art" or in his comparable analyses in Being and Time. While it would go beyond the scope of this paper to try to explain this further, let me just say that while Husserl and Heidegger both view any object of concern as something that can only be understood through our connection to it (e.g. as a cogitatum or as "equipment"), still Husserl's "epistemological" approach focuses more on what it is about a specific object that can arouse our interest than Heidegger's "existential" approach, which focuses more on what it is about us that leads us to be interested in any object whatsoever.

\section{Works Cited}

Heidegger, Martin. The Essence of Truth. Trans. Ted Sadler. New York: Continuum, 2002.

Husserl, Edmund. "The Origin of Geometry." The Crisis of European Sciences and Transcendental Phenomenology. Trans. David Carr. Evanston: Northwestern University Press, 1970. 353-378.

. Ideas Pertaining to a Pure Phenomenology and to a Phenomenological Philosophy, First Book. Trans. Fred Kersten. Dordrecht: Kluwer Academic Publishers, 1998.

Ideas Pertaining to a Pure Phenomenology and to a Phenomenological Philosophy, Second Book. Trans. Richard Rojcewicz and André Schuwer. Dordrecht: Kluwer Academic Publishers, 1989. 
Levinas, Emmanuel. Totality and Infinity. Trans. Alphonso Lingis. Pittsburgh: Duquesne University Press, 1969.

Existence \& Existents. Trans. Alphonso Lingis. Pittsburgh: Duquesne University Press, 1978. 